\title{
The Establishment and Empirical Study of the Mechanism of Influence on the Expatriate Performance of Employees Enterprise
}

\author{
Liangliang Wang \\ International Business School \\ Yunnan University of Finance and \\ Economics \\ Kunming, China \\ 1015792105@qq.Com
}

\author{
Di Yang* \\ Ernst \& Young (China) Advisory \\ Limited \\ charlie.d.yang@cn.ey.com
}

\author{
$\mathrm{Nan} \mathrm{Xu}$ \\ International Business School \\ Yunnan University of Finance \\ and Economics \\ Kunming, China \\ 670952431@qq.com
}

\begin{abstract}
With the continuous growth of the economy and national strength. As the pace of internationalization of Chinese enterprises continues to accelerate, the management of expatriate employees has become a huge challenge for expatriate enterprises and multinational companies. The purpose of this study is to identify the factors that influence the expatriate adaptability and job performance through the investigation of the individual expatriate adaptability and job performance. According to expatriates' ability and the level of cultural intelligence explore that cultural intelligence has a direct impact on job performance, meanwhile, that focuses on the mediating role of expatriate adaptation as a mediator variable and the regulatory effect of emotional intelligence between cultural intelligence and expatriate adaptation, and the regulatory effect of emotional intelligence between cultural intelligence and job performance. Questionnaire survey was used to investigate the overseas situation of Chinese expatriates, and exploratory factor analysis, confirmatory factor analysis, multiple regression and other statistical methods were used to test. The results show that there is a significant positive correlation between cultural intelligence and job performance. For expatriate adaptation, there is a mediating effect between cultural intelligence and job performance, and there is a significant positive correlation between cultural intelligence and expatriate adaptation. Emotional intelligence plays a moderating role in the relationship between cultural intelligence and expatriate adaptation: when the moderating variable emotional intelligence is introduced, the significant positive correlation between cultural intelligence and expatriate adaptation is strengthened. The positive correlation between cq and job performance is strengthened by introducing the moderating variable emotional intelligence.
\end{abstract}

Keywords: cultural intelligence, expatriate performance, emotional intelligence, expatriate adaptation

\section{INTRODUCTION}

In 2001, China officially the world trade organization, China's reform and opening up into a new stage, complied with the trend of economic globalization, for Chinese enterprises to implement internationalization provides policy guarantee, at this stage, the Chinese enterprise rapid development, significantly enhance China's economic strength, provides the internationalization of Chinese enterprises to achieve economic foundation. In 2018, China's GDP grew by 6.6 percent over the previous year, meeting the expected growth target of around 6.5 percent. This growth rate ranks first among the world's top five economies. On March 28, 2015, the National Development and Reform Commission, the Ministry of Foreign Affairs and the Ministry of Commerce jointly issued the vision and action for jointly building the silk road economic belt and the 21st century maritime silk road. Chinese enterprises have gradually become active on the world stage. After the opening of the "One Belt and One Road" economic zone, the number of contracted projects has exceeded 3,000. In 2015, Chinese enterprises made direct investment in 49 countries related to One Belt and One Road, with the investment increasing by $18.2 \%$ year-on-year. In 2015, China undertook service outsourcing contracts of "One Belt and One Road" related countries worth us $\$ 17.83$ billion, with the execution amount of us $\$ 12.15$ billion, up $42.6 \%$ and $23.45 \%$ respectively year-onyear. According to data released by the Ministry of Commerce on January 25, 2018, One Belt and One Road economic and trade cooperation has achieved remarkable results. In 2017, China's trade volume with countries along the belt and road reached 7.4 trillion yuan, up $17.8 \%$ year-on-year. China always adheres to the policy of "going out" and "bringing in". The degree of internationalization of enterprises is constantly improving. Employees of enterprises must communicate in a cross-cultural environment to achieve organizational performance and realize the internationalization of enterprises, which puts forward higher requirements for employees. Under the foreign economic policies of "One Belt and One Road", "going out" and "bringing in", enterprise internationalization has become a trend of enterprise development, and expatriates is the core element of enterprise internationalization. Whether the expatriates can actively adapt to the cross-cultural environment according to their own personality traits will affect whether the expatriates can achieve the goals of the organization and the performance of the organization, which will indirectly affect the market share of the multinational

*Corresponding author 
company, the relationship with the government departments and partners of the host country, etc.

The cultural intelligence, expatriate adaptation, emotional intelligence and expatriate performance are closely related. As the subject of authorized management of enterprises, Chinese expatriates must reflect their ability and quality of investment project management in face of information processing and risk judgment of overseas investment projects. Because cultural differences increase conflict and friction, this cross-cultural interaction can be challenging for individuals and their organizations. International companies increasingly need the ability to interact effectively with people from different cultures to solve problems in a complex international work environment. Therefore, cross-cultural studies increasingly need to solve misunderstandings and conflicts caused by cultural barriers in complex international work environments. In order to solve this practical problem, the cultural intelligence proposed. Expatriate adaptation is an important prerequisite for expatriate performance. The research on the performance of local enterprises is more concerned with the emotional intelligence and leadership style of leaders, but how to establish a dynamic connection between cultural intelligence, assignment adaptation, emotional intelligence and expatriate performance in a cross-cultural context. As a common difference feature of intelligence, intelligence can effectively intervene in multidimensional outcome variables, which has significant dynamic characteristics and makes up for the shortcomings of traditional research, so there is reason to become the new perspective of adaptation and expatriate performance abroad, also is the important basis of the project research.

\section{LITERATURE REVIEW AND RESEARCH PROPOSITION}

\section{A. Cultural Intelligence and Expatriate Performance}

With the deepening of cross-cultural research, researchers focus on individual differences and personality traits. Based on this research background, Earley first proposed the concept of cultural intelligence: cultural intelligence refers to the effective interaction ability of individuals in a multicultural environment [2]. Earley \& Ang to culture the construct of intelligence research from the original $3 \mathrm{~d}$ model for the development of the four-dimensional model: (1)meta-cognitive cultural intelligence, Butterfield considered above "thinking about thinking" [3], Earley \& Peterson as individuals for monitoring and use of the individual has the cognitive understanding of knowledge and strategies, including planning, self-monitoring, and the use of cognitive strategy [4]. (2) cognitive cultural intelligence, as explained by Thomas \& Inkson, means that individuals know what culture is, what cultural differences are and how different cultures affect behaviors, which requires a broad social and cultural knowledge base, including political, economic, religious systems and social relations [5]. (3) motivational cultural intelligence, as explained by Earley \& Peterson, is an individual's willingness to face and contact with different cultures as well as his inner desire to persist in conflict situations [4]. Earley points out that for people with low motivational cultural intelligence, who will be can't adapt the environment. The close relationship between motivation and expatriate adaptation has been widely confirmed in various studies [6][7][8]. (4) Behavior cultural intelligence, Thomas thought to be "a good behavior instruction system" from the instruction system and be able to make informed choices, including the interaction to adapt to the situation of the language and non-language behavior, a man with high cultural intelligence behavior has very strong to imitate ability, that is unconscious or mechanically complete interaction [9]

For the research on expatriate performance, a relatively influential and representative research model is the threedimensional behavior model of Katz's performance [10], and the task-peripheral performance two-dimensional model theory proposed by Borman [11]. The research on performance structure by foreign scholars generally includes three kinds: the research on performance structure of consequentialism, the research on performance structure of behavior and the research on performance structure of synthesis. Bonardin and Norman Flynn are the main representatives of the research on the performance structure of consequentialism. Campbell defined performance as the behaviors or actions of employees that could be evaluated by the organization in the process of achieving organizational goals [12]. Murphy proposed four types of behavioral performance: task-oriented behavior, interpersonal relationship maintenance, non-work behavior and destructive dangerous behavior. Rotundo \& Sacket divides work performance into two dimensions: task performance and non-task performance. The performance structure of Shaffter's behavior theory makes up for the deficiency of the result theory It not only links the behavior of employees with the performance of the organization, but also considers the social behavior and psychological satisfaction of employees [13].

Many studies have proved that individual differences in personality and ability, which have a certain predictive effect on individual work performance. Therefore, individual differences in characteristics, which can be used to explain why some expatriates perform better on assignment than others. Therefore, cultural intelligence can better predict the performance of expatriates in different cultural backgrounds. The individual's characteristics will be aroused in the relevant situation, which will lead to the corresponding behavior. Hui Li and Qun Wang believe that for individuals in different cultural situations, the unfamiliar cultural environment is a specific challenge, and individuals' cognition, learning, enthusiasm and persistence as well as appropriate behavior will become the most important individual characteristics in the context of cultural differences. Therefore, I believe that individuals with high cultural intelligence can cope with the cultural challenges of international assignments and show more effective performance than others in a different cultural environment [14]. According to existed theory and results, this paper propose the following hypothesis:

P1: Higher levels of cultural intelligence will be positively associated with better expatriate performance.

\section{B. The Mediating Effect of Expatriate Adaptation}

Cross-cultural adaptation can be traced back to the proposal of cultural shock. Since the 1980s, the research objects in this field have changed, and the expatriate personnel of multinational companies have received widespread attention. 
Ward\& Kennedy expanded the single dimension of crosscultural adaptation into two dimensions: psychological adaptation and social acculturation[15]. Through the continuous improvement and improvement of their previous research results, Black \& Mendenhall proposed a threedimensional model of social adaptation for expatriates: work adaptation, interactive adaptation and general adaptation [16]. Job adaptation refers to the ability to adjust various jobs and tasks, including taking on new tasks and managing business relationships. Interactive adaptation refers to the degree of comfort and cross-cultural ability of expatriates when they interact with the nationals of the host country during work and after work, such as interpersonal skills to deal with communication differences and language barriers. General adaptation refers to the adaptation of expatriates to the general living conditions and living environment of the host country, such as transportation, food and weather. The three dimensional model of expatriate adaptation has been widely used in the field of expatriate research.

The influence of cultural intelligence on expatriate performance is not only reflected in the direct impact, but also in the influence of cultural intelligence on the degree of crosscultural adaptation of expatriates, which further affects the level of expatriate performance, that is, expatriate adaptation as an intermediary variable. There is also evidence to be found in the study of cross-cultural adaptation for expatriates' performance. Ang et al. found that individuals with high motivational cultural intelligence performed better because they had an inherent interest in learning new culture, which helped them to achieve success in the cross-cultural environment [17]. Malek discussed the role of cultural intelligence as a predictor of expatriate adjustment and its impact on expatriate performance [18]. The non-huff managers as the research object proposed that managers with cultural intelligence could better adapt to the new cultural environment and thus have the ability to perform better. In addition, Jyoti studied the mediating effect of cross-cultural adaptation on cultural intelligence and expatriate performance from the perspective of emigration, which indicated that the relationship between cultural intelligence and expatriate performance was mediated by expatriate adaptation[19]. Expatriate adaptation as a intervening variable between cultural intelligence and expatriate performance research theory is more to the staff of management or emigrated abroad as the research object, study the influence of the foreign parties performance, but the theory is applicable in China under the background of the strategy of "generation" to go out of China enterprise theory is not yet perfect, market performance in the context of expatriate performance to measure not only the individual differences of management abroad, ordinary expats are key points of research object. According to existed theory and results, this paper propose the following hypothesis:

P2: Expatriates adaptation plays a mediating role between cultural intelligence and expatriate performance.

\section{The Moderating Effect of Emotional Intelligence.}

American psychologists Mayer and Salovey put forward the term emotional intelligence. They believe that emotional intelligence is the ability to process emotional information, including the ability to accurately evaluate the emotions of oneself and others, the ability to express emotions appropriately and the ability to regulate emotions adaptively [20]. Mayer and Salovey developed the emotional intelligence scale (MSEIT), and Boyatzis and Goleman successively developed the new emotional intelligence scale (EIT), which was a major breakthrough in emotional intelligence research and established scientific standards for the measurement of emotional intelligence variables. Xu Haiyan adjusted the ownership of variables and the naming of variables based on the actual content measured by the theoretical structure of the dynamic emotional intelligence theoretical model at home and abroad. They adjusted the two variables under the emotional perception dimension into emotional experience and emotional discrimination. The two variables under the emotional application dimension were adjusted to emotional recognition and emotional openness. To sum up, the research on the performance of emotional intelligence in outbound assignments in cross-cultural situations is still in its initial stage.

The research on emotional intelligence on performance focuses on the impact of emotional intelligence on individual task performance or team performance, and the research objects are mostly employees of local enterprises. Jordan found that at the group level, there was a link between emotional intelligence and performance of pure cognitive tasks, although this link did not appear at the individual level. Lyons and Schneider discussed the relationship between emotional intelligence and team performance from the organizational level, and found that employees' emotional intelligence positively promoted team performance. According to these scholars, emotional intelligence is the ability to process one's own emotions, making team members more inclined to listen to different opinions and seek better solutions, thus improving the level of team performance. Janine Black et al. studied the influence of emotional intelligence on expatriate performance, introduced the variable of team cohesion, and believed that the emotional intelligence level of employees could promote the positive interaction between employees, enhance the team cohesion of the company, and thus improve the market performance level of the company. According to existed theory and results, this paper propose the following hypothesis:

P3: Emotional intelligence plays a regulatory role between cultural intelligence and expatriate adaptation.

P4: Emotional intelligence plays a regulatory role between cultural intelligence and expatriate performance.

P5: Emotional intelligence plays a regulatory role between expatriate adaptation and expatriate performance.

In conclusion, this study constructed a moderated mediation model (as shown in figure 1), and examined the relationship between cultural intelligence, expatriate adaptation, emotional intelligence and expatriate performance. Specifically, this study intends to examine the cultural intelligence to predict the performance of expatriate expatriates intermediary (assignment) and regulation (emotional intelligence) mechanism, expatriate performance expectations for clear influence enterprise mechanism and the influence of individual differences, assignment for the enterprise to establish a more scientific and reasonable selection strategy, to improve the level of expatriate 
performance abroad provide empirical support and theoretical guidance.

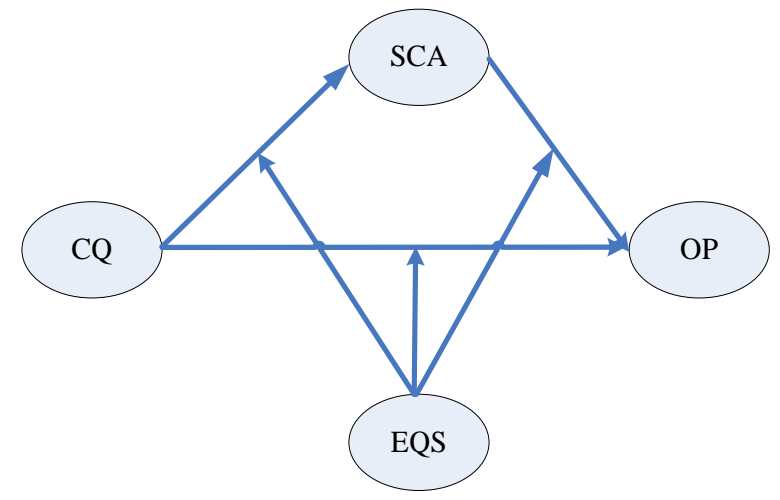

Figure 1. Hypothesis model of mediating effect of expatriate adaptation and regulating effect of emotional intelligence

\section{THE RESEARCH METHODS}

\section{A. Questionnaire Design}

This paper adopts questionnaire survey research method, is proposed to select small depth interview 15 objects, including enterprise unidirectional and bidirectional assignment, project management and non-management staff sample host governments, cooperation with foreign enterprises, and the influence of ethnic group, where the project is located, the elders, religious, informal organization, etc., aim to verify from the viewpoint of practical observation quantitative analysis of the conclusions. A total of 400 questionnaires were distributed in this survey, and 317 valid questionnaires were recovered, accounting for $80 \%$ of the total. In the entire sample, most expatriates were married men. Men made up 76.8 percent of the sample and 76.6 percent of expats were married. There were no significant differences in the distribution of gender, age and marriage in the data sources, and the proportions were consistent with previous studies, namely the proportion of male and female expat population and the proportion of married and unmarried population. Most of the participants in the study were between the ages of 30 and 39. The majority of expats received university degrees (97.8 percent), had worked for 1-3 years (73.8 percent) and had previously stayed in the host country for 1-5 years (46.4 percent).

Likert 5 points were used for all scales in this study. Specific measurement tools of each variable are summarized as follows:

(1) Expatriate adaptation the scale developed by Black and Stephens (1989), which is divided into three dimensions: overall adaptation, interactive adaptation, and job adaptation.

(2) Cultural intelligence developed by Ang (2004) was used to measure individual cultural intelligence.

(3) Adopt the emotional intelligence scale (MSEIT) developed by Mayer and Salovey (2000);

(4) the organizational performance scale developed by Youndt(1996) was used to measure the expatriate performance.

\section{B. The Test of Reliability and Validity}

Reliability refers to the degree of consistency of the results obtained when the same method is repeated for the same object. The Cronbach' Alpha test was generally adopted. When the Cronbach' Alpha coefficient was above 0.7, it was considered to be very reliable. According to the reliability test, the Cronbach' coefficient was 0.853 and greater than 0.8 , indicating that the reliability of the variable was acceptable.

According to Kaiser (1974), the closer the value of KMO is to 1 , the greater the sum of squares of the simple correlation coefficients between all variables is than the sum of squares of partial correlation, so it is more suitable for factor analysis. The closer the value of KMO is to 1 , the better the effect of factor analysis on related variables is. The effect of factor analysis is best when KMO is greater than 0.9 , acceptable when greater than 0.7, and generally inappropriate when less than 0.5. As can be seen from the result of text, KMO value is 0.914 , which is appropriate for factor analysis. Bartlett's sphericity test results showed that the approximate chi-square value was 11844.297 , with significance $\mathrm{p}=0.000<0.05$, indicating that the data obtained from the normal distribution was also suitable for factor analysis.

\section{THE RESULTS}

A. The Mean, Standard Deviation and Correlation Matrix of Each Variable

The results of description and correlation analysis showed that (as show table 1): cultural intelligence was significantly negatively correlated with emotional intelligence, which is positively correlated with expatriate adaptation and expatriate performance; Expatriate adaptation is positively correlated with expatriate performance and negatively correlated with emotional intelligence. There is a significant negative correlation between emotional intelligence and expatriate performance.

TABLE I. DESCRIPTIVE STATISTICS AND CORRELATION ANALYSIS RESULT

\begin{tabular}{|c|c|c|c|c|c|c|}
\hline & M & SD & CQ & EQS & SCA & OP \\
\hline CQ & 2.8 & 1.2 & 1.0 & & & \\
\hline EQS & 3.1 & 1.0 & $-.987^{* *}$ & 1.0 & & \\
\hline SCA & 2.4 & 1.5 & $.497^{* *}$ & $-.499^{* *}$ & 1.0 & \\
\hline OP & 3.1 & 0.4 & $.318^{* *}$ & $-.315^{* *}$ & $.295^{* *}$ & 1.0 \\
\hline
\end{tabular}

B. The Relationship between Cultural Intelligence and Expatriate Performance: A Moderated Intermediary Model Test

At first, Model4 in SPSS macro compiled by Hayes(2012) (Model4 is a simple mediation model) was used to test the mediation effect of expatriate performance in the relationship between cultural intelligence and expatriate performance. The results (as show table 2 and 3 ) showed that cultural intelligence have a significant predictive effect on the expatriate performance $(\mathrm{t}=5.95, \mathrm{p}<0.01)$, and when mediating variables were put in, the direct predictive effect of cultural intelligence on the expatriate performance was significant $(\mathrm{t}=3.74, \mathrm{p}<$ $0.01)$. Cultural intelligence has a significant positive prediction effect on expatriate adaptation $(\mathrm{t}=10.16, \mathrm{p}<0.01)$, and expatriate adaptation also has a significant positive prediction effect on expatriate performance $(\mathrm{t}=2.99, \mathrm{p}<0.01)$. In addition, the mediating effect of cultural intelligence on 
expatriate performance bootstrap $95 \%$ confidence interval does not include 0 (as show table 3 ), The results show that cultural intelligence not only has a direct effect on the expatriate performance, but also has an indirect effect on the expatriate performance through the mediating variable.

TABLE II. INTERMEDIARY MODEL TEST OF EXPATRIATE ADAPTATION

\begin{tabular}{|c|c|c|c|c|c|c|}
\hline $\begin{array}{c}\text { The Regression } \\
\text { Equation } \\
\text { (N=317) }\end{array}$ & \multicolumn{3}{|c|}{ Fitting Index } & \multicolumn{2}{c|}{$\begin{array}{c}\text { Coefficient } \\
\text { Significance }\end{array}$} \\
\hline $\begin{array}{c}\text { Results } \\
\text { variable }\end{array}$ & $\begin{array}{c}\text { Predictor } \\
\text { variable }\end{array}$ & $\boldsymbol{R}$ & $\boldsymbol{R}^{2}$ & $\boldsymbol{F}$ & $\boldsymbol{t}$ & $\boldsymbol{P}$ \\
\hline SCA & & 0.50 & 0.25 & 103.29 & & \\
\hline & CQ & & & & 10.16 & 0.00 \\
\hline OP & & 0.35 & 0.13 & 22.60 & & \\
\hline & CQ & & & & 3.74 & 0.00 \\
\hline & SCA & & & & 2.99 & 0.00 \\
\hline OP & & 0.32 & 0.10 & 35.38 & & \\
\hline & CQ & & & & 5.95 & 0.00 \\
\hline
\end{tabular}

Note: all variables in the model are substituted into the regression equation by standardized variables, the same as below.

TABLE III. TOTAL EFFECT, DiRECT EFFECT AND INTERMEDIATE EFFECT DECOMPOSITION

\begin{tabular}{|c|c|c|c|c|c|}
\hline & Effect & BootSE & BootLLCI & BootULCI & $\begin{array}{c}\text { Relative } \\
\text { Effect } \\
\text { Value }\end{array}$ \\
\hline $\begin{array}{c}\text { Total } \\
\text { Effect }\end{array}$ & 0.12 & 0.02 & 0.02 & 0.09 & \\
\hline $\begin{array}{c}\text { Direct } \\
\text { Effects }\end{array}$ & 0.08 & 0.02 & 0.04 & 0.12 & 0.72 \\
\hline $\begin{array}{c}\text { Indirect } \\
\text { Effects }\end{array}$ & 0.03 & 0.01 & 0.01 & 0.05 & 0.28 \\
\hline
\end{tabular}

Note: Boot standard error, Boot CI lower limit and Boot CI upper limit refer to the standard error of indirect effect estimated by Bootstrap method with deviation correction, and the lower limit and upper limit of $95 \%$ confidence interval respectively.

Secondly, Model59 in SPSS macro compiled by Hayes (assuming that the mediation model is consistent with the theoretical model in this study) was adopted to test the mediation model with adjustments. The results (as show table 4 and 5) show that after adding emotional intelligence into the model, the product term of cultural intelligence and emotional intelligence has a significant predictive effect on expatriate adaptation $(\mathrm{t}=3.08, \mathrm{p}<0.01)$, while the predictive effect on expatriate performance is not significant $(t=1.05, p>0.1)$. In addition, the product term of emotional intelligence and assignment adaptation shows a significant negative correlation with assignment performance $(t=-3.73, \mathrm{p}<0.1)$, indicating that emotional intelligence can not only regulate the prediction function of expatriate adaptation of cultural intelligence, but also play a moderating role in the prediction function of expatriate performance of expatriate adaptation of cultural intelligence. Therefore, hypothesis $1,2,3,5$ are verified, and hypothesis 4 is not
TABLE IV. REgUlating INTERMEDIARy MODEL TEST

\begin{tabular}{|c|c|c|c|c|c|c|}
\hline $\begin{array}{c}\text { The Regression Equation } \\
\text { (N=317) }\end{array}$ & \multicolumn{3}{|c|}{ Fitting Index } & \multicolumn{2}{c|}{$\begin{array}{c}\text { Coefficient } \\
\text { Significance }\end{array}$} \\
\hline $\begin{array}{l}\text { Results } \\
\text { Variable }\end{array}$ & $\begin{array}{c}\text { Predictor } \\
\text { Variable }\end{array}$ & $\boldsymbol{R}$ & $\boldsymbol{R}^{\mathbf{2}}$ & $\boldsymbol{F}$ & $\boldsymbol{t}$ & $\boldsymbol{P}$ \\
\hline SCA & & 0.52 & 0.27 & 38.95 & & \\
\hline & CQ & & & & -1.51 & 0.13 \\
\hline & EQS & & & & -2.48 & 0.01 \\
\hline & CQxEQS & & & & 3.08 & 0.00 \\
\hline OP & & 0.40 & 0.16 & 12.14 & & \\
\hline & CQ & & & & 0.08 & 0.93 \\
\hline & SCA & & & & 4.52 & 0.00 \\
\hline & EQS & & & & 0.44 & 0.66 \\
\hline & CQxEQS & & & & 1.05 & 0.30 \\
\hline & SCAxEQS & & & & -3.73 & 0.00 \\
\hline
\end{tabular}

DiReCt AND MEDiating EFFects at DifFERENT LEVEls of EMOTIONAL INTELLIGENCE

\begin{tabular}{|c|c|c|c|c|c|}
\hline & EQS & Effect & BootSE & BootLLCI & BootULCI \\
\hline Direct & 2.22 & 0.26 & 0.21 & -0.14 & 0.67 \\
\cline { 2 - 6 } Effects & 3.00 & 0.28 & 0.20 & -0.11 & 0.66 \\
\cline { 2 - 6 } & 4.44 & 0.30 & 0.20 & -0.09 & 0.69 \\
\hline \multirow{3}{*}{ Indirect } & 2.22 & -0.04 & 0.04 & -0.12 & 0.05 \\
\cline { 2 - 6 } & 3.00 & 0.00 & 0.04 & -0.09 & 0.08 \\
\cline { 2 - 6 } & 4.44 & 0.06 & 0.05 & -0.04 & 0.15 \\
\hline
\end{tabular}

\section{CONCLUSION}

In the cross-cultural working environment, due to the changes in the working environment, cultural environment and living environment, many difficulties and obstacles will arise, leading to the negative attitude and frustration of the expatriates, which is exactly the key to the poor performance of the expatriates. The current stage is the key period of "One Belt and One Road" strategy. Chinese enterprises firmly seize this opportunity to realize the "going global" of Chinese enterprises. The choice of expatriate personnel is the key point for enterprises to realize regional expansion. How to solve the existing problems of the dispatched personnel, and formulate the corresponding solution measures and selection standards, will play an important role in promoting the performance of the dispatched personnel. The research results of this paper show that :(1)Higher levels of cultural intelligence will be positively associated with better expatriate performance. (2) Expatriates adaptation plays a mediating role between cultural intelligence and expatriate performance. (3)Emotional intelligence plays a regulatory role between cultural intelligence and expatriate adaptation, which plays a regulatory role between expatriate adaptation and expatriate performance. When choosing expatriate staff in Yunnan enterprises, they should not only measure the cultural intelligence level of the dispatched staff, but also comprehensively consider the cultural intelligence and emotional intelligence level of the dispatched staff, so as to improve the adaptability of the dispatched staff and the performance level of the dispatched enterprise.

\section{ACKNOWLEDGMENT}

Funding for this research was provided by National Natural Science Foundation of China under grants 71762033. The facilitation from international collaborative program and cooperation with Charles Sturt University in Australia is gratefully acknowledged. The assistance of Professor Mark 
Frost and Antony Bush and comments from an associate editor and two anonymous reviewers are also acknowledged.

\section{REFERENCES}

[1] Earley, P.C. and Ang, S. (2003), Cultural Intelligence: An Analysis of Individual Interactions across Cultures, Stanford University Press, Palo Alto, CA.

[2] Zhang, Y\& Zhou, W. An asymmetric cross-cultural perspective on the mediating role of conflict management styles in expatriation. International Journal of Conflict Management,28(05),592-616.

[3] Butterfield, E. C. (1994)., Encyclopedia of human intelligence (pp. 725732). New York: Macmillan, Inc.

[4] Earley, C., \& Peterson, R. S. (2004). The elusive cultural chameleon: Cultural intelligence as a new approach to intercultural training for the global manager. Academy of Management Learning \& Education, 3(1), 100-115.

[5] Thomas, D. C., \& Inkson, K. (2004). Cultural intelligence: People skills for global business. San Francisco, CA: Berrett-Koehler.

[6] Smith, B., \& Bond, M. H. (1999). Social psychology across cultures: Analysis and perspectives. New York: Pearson Allyn and Bacon.

[7] Adler, N. (2002). From Boston to Beijing: Managing with a world view. Cincinnati, Ohio: South-Western, Thomson Learning.

[8] Zhang, Y. Exploring the potential effects of expatriate adjustment direction. Cross-Cultural Management: An Internaitonal Journal, 2016, 23(1) : 158-183. SSCI, IF 0.855.

[9] Thomas, D.C. Domain and Development of Cultural Intelligence: The Importance of Mindfulness[J]. Group \& Organization Management, 2006, 31(1):78-99.
[10] Katz D.\& Kahn, R L. The social psychology of organizations. New York.Wiley,1978.

[11] Borman. Task performance and Contextual Performance: The Meaning for Personnel Selection Research Human Performance, 1997,10(2):99109.

[12] Campbell, J. P., etc. A Theory of performance [C]. Schmitt Nand Borman W C. Personnel Selection in Organizations.San Francisco: Jossey-Bass Publishers, 1993.

[13] Shaffer L G , Kashork C D, Saleki R, et al. Targeted genomic microarray analysis for identification of chromosome abnormalities in 1500 consecutive clinical cases[J]. Journal of Pediatrics, 2006, 149(1):010200000 .

[14] Li hui, Wang qun. A study on the influence of expatriates' cultural intelligence on their performance -- an empirical study based on China's "going global" enterprises [J]. Forecast, 2018(2):1-8.

[15] Ward, C., Kennedy, A. The Measurement of Socio-cultural Adaptation [J]. International Journal of Intercultura1 Relations, 1999, 23(4): 659-77.

[16] Malek, M.A. and Budhwar, P. (2013), "Cultural intelligence as a predictor of expatriate adjustment and performance in Malaysia", Journal of World Business, Vol. 48 No. 2, pp. 222-231.

[17] Mayer, J.D., Caruso, D.R. and Salovey, P. (1997), "Emotional intelligence meets traditional standards for an intelligence", Intelligence, Vol. 27 No. 4, pp. 267-98.

[18] Boyatzis,R.E. and Goleman, D. (2002), The Emotional Competency Inventory, The Hay Group, Boston, MA.

[19] Xu Haiyan, Qiao Lan, Wang Xiaojun. Development and empirical research of emotional intelligence assessment scale? Journal of Ping Xiang University,2016,33(01):106-110.

[20] Lyons J B, Schneider T R. The influence of emotional intelligence on performance[J]. Personality \& Individual Differences, 2005, 39(4):693703. 